\title{
ESTRATÉGIAS DE INOVAÇÃO DAS STARTUPS GLOBAL BORNS: um estudo comparativo com empresas incubadas
}

\author{
L. F. L. G. COSTA, C. M. F. A. RIBEIRO, J. L. SILVA, V.D. ARAÚJO JÚNIOR e R.F. PIRES \\ Instituto Federal de Educação, Ciência e Tecnologia do Rio Grande do Norte \\ lucia.lucio@ifrn.edu.br, claudia.ribeiro@ifrn.edu.br, jupiara_lima@hotmail.com, junindantas@hotmail.com, \\ ressu_pires@hotmail.com
}

Artigo submetido em agosto/2015 e aceito em setembro/2015

DOI: 10.15628/empiricabr.2015.3326

\section{RESUMO}

O presente artigo tem como objetivo analisar as estratégias das empresas nascentes com orientação para o mercado internacional, as global borns. Para tanto, foi realizada uma pesquisa qualitativa, cuja estratégia foi um estudo de caso múltiplo com cinco startups incubadas em duas incubadoras. Como aporte teórico sobre movimento de startups se decidiu investigar por meio de duas abordagens: o empreendedorismo e o processo de internacionalização, esta segunda abordagem pode ser analisada por meio das linhas econômicas e comportamentais da internacionalização. Como principal contribuição pode-se perceber que as empresas nascente ainda estão em estágio embrionário em relação processo de internacionalização, porém o que se percebe é um esforço em estabelecer condições para que o projeto seja escalável. Dessa forma, tanto o modelo de receita quanto a estratégia de escalonamento visam padrões inovadores para que possam entrar em outro momento do projeto

PALAVRAS-CHAVE: Estratégia; Internacionalização; Empreendedorismo; Global-borns; Startups

\section{INNOVATION STRATEGY OF GLOBAL STARTUPS BORNS: a comparative study wich incubated companies}

\begin{abstract}
This article aims to analyze the strategies of emerging entrepreneurs with guidance for the international market, the global borns. To that end, we conducted a qualitative research, whose strategy was a multiple case with five incubated startups in two incubators. As theoretical precepts of recent phenomenon that the movement of startups decided to investigate through two approaches entrepreneurship and the
\end{abstract} analyzed by means of economic and behavioral lines of internationalization. As main contribution can be seen that the rising companies are still in an embryonic stage in relation internationalization process but what we see is an effort to establish conditions for the project to be scalable. Thus, both the revenue model as the scheduling strategy aimed at innovative standards so that they can come at another time of the project.

KEYWORDS: Strategy; Internationalization; Entrepreneurship; Global-borns; Startups 


\section{INTRODUÇÃO}

O processo estratégico internacional não depende apenas de especificidades do mercado, de vantagens específicas da firma, ou de um arranjo de fatores que se manifestam segundo critérios objetivos de decisão de escolha dos modos de entrada. A implementação unilateral pelo entrante no mercado estrangeiro, não garante que a firma possa obter sucesso no mercado internacional, haja vista que, a decisão por uma dessas vantagens comparativas poderá comprometer o êxito em função de outra (Honório, 2009). O processo inclui também a escolha de relacionamentos que thes produza maior vantagem de acesso a recursos valiosos em toda sua cadeia de clientes, fornecedores, distribuidores e agências governamentais (JOHANSON; MATTSSON, 1988; ROOT, 1994; BARNEY, 2006).

Mesmo diante de muitas abordagens diferentes, entende-se que o processo estratégico internacional é determinado por características organizacionais específicas e que o conjunto dessas perspectivas se revela como um importante influenciador do grau em que se encontra a extensão das operações internacionais, usualmente avaliado por meio de indicadores financeiros e operacionais (PREVIDELLI, 1997; HONÓRIO, 2009). A medida que as atividades internacionais vão se expandindo, o grau de internacionalização se modifica e aprimora em termos financeiros e de negócios efetivados no exterior, oportunizando a ampliação do escopo geográfico onde eles se concentram. Isso se justifica pelo desenvolvimento de know-how do negócio e pela reestruturação de competências empresariais (KOGUT, 2002).

Estudos recentes têm apresentado uma nova perspectiva acerca do fenômeno da internacionalização. A partir da década de 90 , observou-se um movimento crescente de empresas que se internacionalizavam cada vez mais cedo ou que já nasciam realizando negócios internacionais, as chamadas empresas born global. Nesse sentido, percebe-se a evolução e a mudança de paradigma das estratégias organizacionais e até do próprio conceito de internacionalização (OVIATT e MCDOUGAL, 1994; KNIGHT e CAVUSGIL, 2004).

Seguindo a mesma dinâmica das empresas nascidas globais, no campo da tecnologia da informação essas organizações assumem outra nomenclatura, as chamadas startups, que são organizações que surgem com alto poder de manobra (adaptação às mudanças do mercado) e flexibilidade apoiada em ferramentas tecnológicas que tem revolucionado as formas de negócios, conceitos de produtos e, principalmente na prestação desses serviços (KIM, 2005; TURBAN, 2004; OSTERWALDER, 2011).

O conceito startup pretende designar empresas recém-criadas que se encontram em fase de desenvolvimento e identificação de mercado. Caracterizadas por serem inovadoras e apresentam elevado risco que do padrão de produto, apesar disso, estas empresas apresentam um custo operacional baixo e e possuem condições de escalonamento de negócio (REIS, 2012).

Considerando o surgimento de empresas startups e born-global no mercado local, e mais especificamente em uma incubadora de empresas situada em um instituto de caráter tecnológico, este trabalho teve como objetivo analisar como as estratégias inovadoras de internacionalização são formuladas e implementadas pelas statups global born. 


\section{REFERENCIAL TEÓRICO}

O fenômeno da internacionalização é uma discussão a qual se remete aos preceitos da teoria do comércio internacional, que surgiu da necessidade de explicação das trocas internacionais. Remonta aos autores clássicos, com realce para as construções de Adam Smith e David Ricardo, o desenvolvimento de uma análise de generalização a qualquer país, assim se contrapondo às concepções protecionistas dos mercantilistas de uma teoria do comércio internacional de validade universal. Abordagens comportamentais e econômicas sobre o fenômeno internacionalização

As décadas de 60, 70 e 80 foram marcadas por produções de abordagens da internacionalização econômicas e comportamentais. Essas abordagens por sua vez dão sequência a um estudo que tem como objeto de análise a organização.

As teorias econômicas basicamente remontavam discussões do ponto de vista quantitativo de como as organizações logravam êxito no processo de internacionalização, que é o caso das pesquisas de Vernon (1966), Hymer (1976), Buckley e Casson (1979) e Dunning (1980).

Vernon (1966) buscou analisar o processo de internacionalização da firma através do ciclo de vida do produto. Para o autor, dependendo do nível de maturidade da indústria, o processo de importação seguido por produção, amadurecimento do produto e exportação, ocorre de forma mais rápida.

A pesquisa empreendida por Hymer (1976), a Teoria da Vantagem Monopolista, argumenta que as empresas multinacionais existem por serem fontes de superioridade sobre empresas estrangeiras em seus próprios mercados. Argumento esse que impulsiona a internacionalização, pois é baseado no pressuposto de que a utilização dessas vantagens monopolistas em mercados externos terá um pequeno custo adicional em relação aos custos do mercado doméstico.

Segundo o autor, as vantagens monopolistas das empresas multinacionais agregam os recursos intangíveis das organizações como: tecnologia, patentes, marcas, recursos humanos, entre outros. Esses recursos estão ligados diretamente ao desenvolvimento de um conhecimento superior, que por sua vez, pode ser transferido para o exterior com baixos custos.

Bucley e Casson (1979) são uma das grandes referências na área e se destacam por explicar e prever os métodos de atendimento do mercado das empresas multinacionais. Para eles, um mercado nacional pode ser atendido de quatro maneiras principais: através de empresas domésticas, de subsidiárias de multinacionais, de empresas nacionais que comercializam produtos importados e por importação direta de multinacionais.

O Paradigma eclético de Dunning é uma tentativa de também envolver aspectos comportamentais a sua teoria, por essa razão é considerado "eclético". No entanto, a ênfase dada ao seu estudo é categoricamente econômica e se destaca principalmente por compreender a localização como uma variável de destaque para o processo de internacionalização. Na pesquisa de Dunning (1980), as variáveis observadas têm significância em relação à internacionalização de empresas americanas e o potencial exportador tem maior importância para países menos desenvolvidos. Além da localização, o estudo também observa características específicas da empresa. 
De uma forma geral, analisando as abordagens modernas da internacionalização de empresas, esses estudos de cunho econômico estão voltados para dimensões de análise da perspectiva interna da organização semelhante à teoria baseada em recursos, principalmente a recursos tangíveis como os aspectos de estrutura organizacional.

A abordagem comportamental é contemplada pelas pesquisas de Johanson e Vahlne (1977); Hallén e Wiedersheim-Paul (1979) e Czinnkota(1985). A Escola de Upsalla, conhecida pelos estudos sobre internacionalização, apresentou a pesquisa de Johanson e Vahlne acerca do gradualismo do processo de internacionalização. Para os autores, a internacionalização é um fenômeno gradual que assume basicamente quatro estágios: exportação indireta, exportação direta, joint venture internacional e investimento direto no país estrangeiro - IDE. Esse processo está diretamente relacionado com o nível de confiança desenvolvido pela empresa à medida que aumenta seu nível de comprometimento com o mercado internacional.

\subsection{Fenômeno Global born e startups}

A partir dos anos 90 observa-se uma nova tendência de mudança no padrão do fenômeno internacionalização. Em virtude do movimento frenético dos mercados, fruto das mudanças históricas de aberturas dos portos de muitos países que saia de uma visão do mundo Bipolar que ainda se ventilava no pós Guerra-fria, se observou uma tendência à modernização das indústrias e uma maior globalização econômica.

Em consequência dessa maior dinâmica, a indústria passa a se modernizar e a propor um modelo de competição ainda mais acirrado, resultando na mudança paradigmática no conceito de internacionalização conhecida como o fenômeno das born global, as empresas nascidas já internacionalizadas que apresentam seus projetos a partir de decisões estratégicas desde seu nascedouro. Uma pesquisa clássica sobre esse movimento é o estudo empreendido por Oviatt e McDougall (1994).

As born global ou global born ou ainda estratégias globais, são terminologias de abordagens teóricas que buscam descrever a internacionalização como fenômeno organizacional que passa a fazer parte da base estratégica, assim como outras unidades de análise dos negócios organizacionais. Dito de outro modo, os negócios organizacionais não são mais uma divisão das estratégias da empresa e sim parte contida na própria estratégia organizacional.

Com o advento da inovação tecnológica e pessoas capacitadas para desenvolver negociações internacionais, apoiadas pelo desenvolvimento do conhecimento nas organizações, foi oportunizado um espaço para a mudança da concepção das multinacionais, que até a década de 90, eram vistas como firmas domésticas grandes e maduras (Kim, 2005; Turban, 2004).

Os meios de comunicação cada vez mais sofisticados, não só nos mercados de capitais (que até então apresentava certa velocidade em comunicação), mas também para rotina das empresas, trouxe a possibilidade de dirigir firmas em qualquer parte do globo. Isso deu origem a empreendimentos novos, que embora tenham uma visão baseada em custos de transação e recursos limitados, poderão dinamizar formas organizacionais que outrora só operariam no mercado de sua origem. (OVIATT e MCDOUGALL, 1994).

Os modos de entrada no mercado internacional (ROTT, 1994) através de mecanismos de alianças estratégicas permanecem referenciando algumas maneiras de se inserir nessa arena. $O$ 
exemplo disso, as joint ventures, pode ter grande aplicação no caso das empresas global born, no entanto, muito do que foi estabelecido para os modos de entradas está pautado no gradualismo da abordagem comportamental da internacionalização.

A formação das estratégias, por sua vez, respeita a dinâmica de uma frenética necessidade de manobra, que são movimentos de estratégias emergentes fruto das oportunidades de mercado, demarcada por escolhas adaptativas (CHANDLER, 1962; MINTZBERG e WATERS,1985; SCHUMPETER, 1985; LAM e WHITE, 1999). A abordagem teórica que traduz a evolução do conceito de internacionalização, as chamadas global born, buscam nas bases teóricas da estratégia competitiva respaldo para a explicação de suas variáveis em estudo.

A abordagem empreendedora orquestrada por Shumpeter na década de 50 toma maior impulso nos anos 2000 através das adaptação das estratégias organizacionais ao novo modelo de mercado. as startups (empresas nascentes) podem ser a oportunidade para o empreendedor que deseja pôr suas habilidades de administrador em prática com um novo produto ou serviço. A startup é uma instituição humana elaborada para a criação de novos produtos e serviços sob condições de extrema incerteza, sua função principal é transformar ideias em produtos, controlar como o mercado reage (REIS, 2012; KIM, 2005; TURBAN, 2004; OSTERWALDER, 2011).

De modo complementar e explanador de conhecimento, o fenômeno startups, está voltado para diversos fatores, como a importância que os gestores dão aos detalhes que fazem parte do desenvolvimento do produto, seja pelo lado de fornecer condições de trabalho adequadas aos profissionais, ou pelas novas técnicas de trabalho, onde não existem horários ou locais de trabalho específico, o objetivo é desenvolver e criar. O ponto central de uma startup, está no cérebro que toma as decisões por trás desta, pois o gestor e sua equipe, sendo a equipe o principal bem que esta pode ter, é um fator de extrema importância no estudo desse projeto, como veremos nos fatores delimitados a seguir, observaremos que o sucesso, assim como o de qualquer empresa está diretamente ligada a capacidade de gestão e criação do líder. Muitos outros fatores estão ligados diretamente a essa capacidade empreendedora, como veremos no quadro a seguir que demonstra quais as principais características em grau de importância para cada perfil estudado.

\section{METODOLOGIA}

Para o alcance dos objetivos propostos foi realizada uma investigação qualitativa através de estudo de casos múltiplo (Yin, 2001) com cinco startups, duas da Incubadora Metrópole Digital IMD na Universidade Federal do Rio Grande do Norte - UFRN e três da Incubadora Tecnológica Natal Central - ITNC do Instituto Federal de Educação, Ciência e Tecnologia do RN - IFRN. A decisão por fazer uma pesquisa qualitativa se dá pela necessidade de conhecer o novo fenômeno organizacional por meio da construção das estratégias organizacionais. Por se tratar de uma investigação inicial e de poucos achados literários sobre os novos fenômenos, a pesquisa em questão tem o caráter descritivo-exploratória (VERGARA, 2009) quanto aos seus fins.

Após a identificação dos casos múltiplos analisados, foi realizada entrevista semiestruturada com as categorias de análises próprias da pesquisa para aplicações das teorias vigentes. Em segundo turno, foi realizada entrevista em profundidade para que o entrevistado pudesse discorrer livremente sobre o tema, oportunizando o surgimento de novas variáveis que não foram contempladas na estrutura inicial (LAKATOS e MARCONI, 2003). Após a coleta de dados, 
estas informações foram tratadas com a técnica de análise de conteúdo (BARDIN, 2004) na busca de realizar a verificação as teorias postas sobre estratégias organizacionais e na identificação de categorias empíricas que possam contribuir para construção de novas abordagens teóricas.

\section{ANÁLISE DE RESULTADOS}

Partindo do entendimento deste, o fenômeno startups é um acontecimento novo, não sendo nada mais que uma forma inovadora de adentrar no mercado internacional, o conceito startups, está diretamente ligada ao empreendedorismo. Nesse sentido, como resultados dessa pesquisa, buscou-se sintetizar categorias de análise relacionadas ao conceito startups voltado para a compreensão do modelo de negócio e estratégia organizacional para a compreensão estágio de cada empreendimento com vista observar aspectos de estratégias de internacionalização no estágio de replicação e escalonamento do modelo.

Assim forem identificadas oito categorias de análise: motivação para empreender, diferenciais organizacionais, mentoria, investimentos, diferenciais de produtos e serviços, ambiente, liderança e estratégia. A decisão por essas categorias de análise se deu por entender que nas estratégias de negócios estão relacionadas com esses conceitos em qualquer que seja o estágio do empreendimento, além disso, a percepção dessas variáveis permitiu a análise do estágio de amadurecimento de cada projeto e seus fatores intervenientes. A última categoria foi modificada ao longo da pesquisa apenas para "estratégia" (anteriormente se chamou de estratégia internacional) por perceber que o grupo de startups em análise ainda está em processo de préescalonamento dos projetos.

A seguir, o Quadro 1 apresenta uma síntese dos resultados alcançados de todas as startups segundo essas categorias de análise. Para manter o sigilo sobre os projetos que tem caráter estratégicos decidiu-se denominar as empresas como A, B, C, D e E

Quadro 1. Análise do discurso das Startups

\begin{tabular}{|c|c|c|}
\hline Startups & Pressuposto Teórico & Percepção da Startup \\
\hline \multicolumn{3}{|r|}{ 1. Motivação para empreender } \\
\hline A & \multirow{5}{*}{$\begin{array}{l}\text { Condições pessoais e } \\
\text { mercadológicas que } \\
\text { orientam o } \\
\text { empreendimento. }\end{array}$} & Surgiu como empreendimento de oportunidade. \\
\hline B & & $\begin{array}{l}\text { Surgiu como oportunidade secundária ao serviço prestado na } \\
\text { área de saúde. }\end{array}$ \\
\hline C & & $\begin{array}{l}\text { fase pré-conceitual que foi consequência da necessidade de } \\
\text { pivotar devido a mudanças no mercado. }\end{array}$ \\
\hline D & & Busca do modelo escalável e replicável \\
\hline $\mathbf{E}$ & & A ideia inicial surgiu por meio de uma pesquisa acadêmica. \\
\hline \multicolumn{3}{|r|}{ 2. Diferenciais organizacionais } \\
\hline A & \multirow{5}{*}{$\begin{array}{l}\text { Vantagem competitiva } \\
\text { do da organização. }\end{array}$} & $\begin{array}{l}\text { O serviço inovador que muda o padrão de atendimento de casas } \\
\text { noturnas. }\end{array}$ \\
\hline B & & Equipe preparada e conhecimento da área de atuação. \\
\hline C & & Adaptação as demandas do mercado. \\
\hline D & & $\begin{array}{l}\text { informações para o setor jurídico e pessoas que necessitam } \\
\text { monitorar o processo. }\end{array}$ \\
\hline E & & Modelo de ensino inovador. \\
\hline \multicolumn{3}{|r|}{ 3. Mentoria } \\
\hline A & \multirow{3}{*}{$\begin{array}{l}\text { Orientadores do } \\
\text { empreendimento. }\end{array}$} & $\begin{array}{l}\text { A mentoria institucional teve um papel importante para o } \\
\text { reconhecimento do potencial de negócio. }\end{array}$ \\
\hline B & & A incubadora exerce papel de mentor institucional. \\
\hline C & & Mentoria e o ambiente inovador. \\
\hline
\end{tabular}




\begin{tabular}{|c|c|c|}
\hline D & & Considera a mentoria uma consequência do ambiente \\
\hline$E$ & & $\begin{array}{l}\text { A mentoria da incubadora ajuda no desenvolvimento da } \\
\text { empresa. }\end{array}$ \\
\hline & & 4. Investimentos \\
\hline A & \multirow{5}{*}{$\begin{array}{l}\text { Acesso a investimento, } \\
\text { investidores anjos e } \\
\text { capital próprio. }\end{array}$} & $\begin{array}{l}\text { Por meio de editais se buscou investimento iniciais e o uso de } \\
\text { capital próprio. }\end{array}$ \\
\hline B & & Investimento de capital próprio. \\
\hline C & & Capital próprio com parceria estrangeira. \\
\hline D & & Capital próprio. \\
\hline $\mathbf{E}$ & & $\begin{array}{l}\text { Por meio de editais se buscou investimento iniciais e o uso de } \\
\text { capital próprio. }\end{array}$ \\
\hline
\end{tabular}

\section{Diferencial de produto/serviço}

\section{A}

B
C
D

E

Vantagem competitiva do produto ou serviço entrante.

A otimização dos processos que envolvem: pedidos pagamentos e cardápios.

Filtro máximo de informações para que permaneçam apenas dados necessários e relevantes.

Fase de adaptação após pivotar.

Ferramenta que aperfeiçoe a manipulação de processos jurídicos.

Desenvolve material de ensino de robótica para crianças e adolescentes de uma maneira multidisciplinar.

\section{Ambiente}

A

Aspectos mercadológicos, de localização e condições

C D favorecem.

E

A

B Aspectos

C

D

E

O ambiente da incubadora é fértil para o desenvolvimento de novas ideias.

O ambiente de atuação é motivador e ajuda na capacitação em gestão.

Ambiente inovador faz diferença no desenvolvimento da empresa.

Ambiente funciona como catalizador de processos.

A incubadora otimiza processos e ajuda no desenvolvimento do empreendimento.

\section{Liderança}

O empreendimento surgiu com um dos sócios, mas todo, ao seu modo, exerce liderança.

comportamentais do A equipe possui uma hierarquia horizontal com uma visão empreendedor e da empreendedora.

equipe. $\quad$ A equipe possui uma hierarquia vertical com diretoria definida além de uma visão empreendedora.

Liderança empreendedora apoiada em conhecimento técnico.

\section{Estratégia}

Atualmente se busca expansão local e alternativa de ampliação

B

C

D

E
Diretrizes de ações competitivas para alcance do mercado e internacionalização dessa fronteira se visualiza pelas plataformas de interação disponíveis no mercado.

Utiliza estratégia de divulgação em nível local.

Busca de oportunidades latentes.

Estratégia de mercado ainda em desenvolvimento Busca do modelo escalável e repetitivo.

Resultados da Pesquisa

Tomando como base a primeira variável sobre o interesse de empreender percebeu-se que a maioria dos respondentes consideram o seu tipo de empreendimento como empreendimento de oportunidade (CHANDLER, 1962; MINTZBERG e WATERS,1985; SCHUMPETER, 1985; LAM e WHITE, 1999) dentro da área de atuação e seria essa a principal motivação para iniciar um novo negócio. O que pode ser observado na fala do empreendedor da Startup B: "Possui como 
diferencial competitivo o baixo custo , o armazenamento de informação (big data) , o know how e expertise das novas tecnologias aplicada a este nicho de mercado." Em relação aos diferenciais organizacionais, todas as empresas consideram atender uma demanda latente de mercado com um modelo de negócio inovador (OVIATT e MCDOUGALL, 1994). O que se percebe, no entanto é que todas as empresas, em seu modelo de receita, operam de forma tradicional com prestação direta de serviço.

Todas as empresas consideram a mentoria como algo fundamental para êxito de um projeto nascente e que as incubadoras exercem esse papel como um "mentor institucional" na orientação para melhores ferramentas de gestão do negócio.

Os editais de financiamento internos e externos a instituição das incubadoras e o capital próprio são as principais fontes de investimentos das empresas das startups em estudo. Uma delas, no entanto, contou com capital estrangeiro (JOHANSON e VALHNE, 1977). Isso pode ser evidenciado na fala do empreendedor da empresa E: “...empresa foi citado capital próprio advindos de atividades relacionadas a ideia inicial no exterior, mais precisamente em Angola."

A maior parte das empresas desenvolvem soluções tecnológicas assessórias a cadeias de suprimentos e produção já existente, desse modo visam contribuir com a melhoria de algum tipo de processo pré-existente. Uma das startups se dedica da prestação de serviço na educação de forma inovadora no ensino de Robótica para crianças e funciona como um projeto ligado as ações da Universidade Federal do Rio Grande do Norte.

Ao serem perguntados sobre o ambiente tarefa, ambiente mercadológico ou de operações, as startups explicaram exclusivamente sobre o ambiente organizacional da incubadoras que funcionam como ambiente colaborativo de inovação (DUNNING, 1980).

Os empreendedores das startups consideram-se lideres no projetos, com equipes que possuem características de lideranças e que julgam importante para a execução do projeto.

Em relação a estratégia observou-se que os empreendimentos estão em busca de modelos escaláveis e que as iniciativas de marketing ainda estão em processo de validação voltadas para o mercado local. Como pode-se observar na fala do empreendedor da empresa A:

A empresa está em fase de startup, pois ainda está em busca de um modelo de negócio, de ser escalável e replicável. Em que a empresa encontrou uma boa base, o que falta é consolidá-la, verificando se os canais estão certos, se a forma de chegar ao cliente está adequada, se a dor do cliente está sendo atendida com a solução disposta pela empresa. Consolidando esta fase de verificação, a fase seguinte será a produção de escala. Em que o objetivo é tornar-se uma grande empresa.

Os resultados observados direcionam para outros aspectos da pesquisa de um estágio que antecede o estágio que as classificariam como global borns. Porém, percebe-se uma rica amostra para a compreensão da construção do conhecimento e o processo de formação de estratégias emergentes. 


\section{CONSIDERAÇÕES FINAIS}

Estudos acerca da internacionalização de empresas já foram desenvolvidos de forma sistemática, desde a década de 70 quando as escolas comportamentais e econômicas se esforçavam para determinar um modelo próprio que definiam as estratégias de internacionalização de empresa, porém só a partir das décadas de 90 é que o fenômeno das empresas nascidas globais ganha destaque dando início a uma nova forma de compreender as estratégias internacionais.

Nesse sentido, não há um consenso científico em relação a dinâmica estratégica deste novo padrão de organização que apresenta uma dinâmica diferenciada. Nos anos 2000, essas empresas nascidas globais apresentam novamente uma forma diferente de se estabelecer, pautada em um alto nível tecnológico, as startups. Assim, do ponto de vista científico, o objeto de estudo oportunizou aspectos importantes para compreensão do fenômeno global born.

Deste modo, se buscou tornar mais claro os procedimentos bem sucedidos que trazem novas perspectivas teóricas para embasar outros empreendimentos desta natureza.

Do ponto de vista socioeconômico, o surgimento de novos empreendimentos deste tipo, que tenham maior respaldo prático e teórico de como desenvolver sua estratégia, oportuniza um conhecimento que agrega competências na área de aplicação. Além disso, permitiu reconhecer mais um fenômeno social aplicado no ambiente organizacional, uma vez que essa natureza inovadora reflete aspectos da sociedade moderna que faz uso de novas tecnologias.

Em termos de alcance dos objetivos da pesquisa, foi identificado o padrão da formação das estratégias de implementação de startups com orientação para o mercado internacional. Isso se deu por meio de estratégias empreendedoras emergentes de ingresso no mercado e estratégias deliberadas ao se observar a possibilidade de escalonamento do modelo de negócio.

Ao estudar as práticas de inovação que nortearam a decisão de empreender das startups percebeu-se que todas inovam na concepção do conceito do serviço e ou produto, porém apresentam modelos de receita da forma tradicional, ou seja, venda direta de produto ou serviço. A inovação no produto e serviço denotam que esses empreendedores buscam iniciar empreendimentos em oceanos azuis.

As teorias explicativas sobre os aspectos motivacionais e de liderança foram todas corroboradas segundo o discurso dos empreendedores. Desse modo, verificou-se que esse aspectos intrínsecos ao empreendedor influenciam as diretrizes da estratégias para o mercado.

Em relação a orientação para o mercado internacional, percebeu-se que para o estágio do empreendimento essa é uma aspiração futura uma vez que se busca desenvolver um negócio replicável, porém a maior parte dos esforços está no processo de validação do modelo.

Assim pode-se compreender o padrão da formação e implementação das estratégias inovadoras de empresas startups global borns observando principalmente seu estágio inicial de validação e de inserção no mercado prioritariamente local com objetivos de escalonamento futuro.

\section{REFERENCIAS}

1. BLANK, S. DORF, B. The Startup Owner's Manual. Ed. Alta Books, 2012 
2. BARDIN. Laurence. Análise de conteúdo. Lisboa. Edições 70, 2004

3. BUCKLEY, P. J.; CASSON, M. C. Analysing foreign market entry strategies: extendind the internalization approach. Journal of International Business Studies, v. 29, n. 3, p. 539-562, 1998.

4. CHANDLER, A.D. Strategy and structure: chapters in the history of the American industry. Cambridge, MA: Harvard University Press, 1962.

5. DUNNING, J. H. Toward an eclectic theory of international production: some empirical tests. Journal of International Business Studies, n. 11, spring- summer, p. 9-31, 1980.

6. HONÓRIO, Luiz Calos. Determinantes Organizacionais e Estratégicos do Grau de Internacionalização das empresas braceleiras. RAE, São Paulo, v. 49, n. 2, p.162-175, abr. 2009.

7. JOHANSON, J; MATTSSON, L. G. Internationalization in industrial systems:

8. JOHANSON, J; WIEDERSHEIM-PAUL, F. The internationalization of the firm: four Swedish cases. The Journal of Management Studies, p. 305322, 1975.

9. JOHANSON, J. and VAHLNE, J. E. The Internationalization Process of the Firm - A Model of Knowledge Development and Increasing Foreign Market Commitments. Journal of International Business Studies. Vol. 8, n.1, 1977, pp 23-32.

10. KIM, W. C., \& Mauborgne, R. A estratégia do oceano azul: como criar novos mercados e tornar a concorrência irrelevante. Rio de Janeiro: Elsevier. 2005.

11. KNIGHT, G.A; CAVUSGIL, S. T. Innovation, organizational capabilities, and the born-global firm. Journal of International Business Studies. 35, 124-141, 2004.

12. KUHN, T. S. A estrutura das revoluções científicas. 4. ed. São Paulo: Perspectiva, 1996.

13. KOGUT, B.; ZANDER, U. Knowledge of the firm, combinative capacities and the replication of technology. Organization Science, v. 3, p. 383-397, 1992.

14. LAKATOS, Eva Maria; MARCONI, Marina de Andrade e. Fundamentos de metodologia científica. 5. ed. São Paulo: Atlas, 2003

15. MINTZBERG, H. A criação artesanal da Estratégia. In: MONTGOMERY, C. A.; PORTER, M. E (Orgs). Estratégia: a busca da vantagem competitiva. Rio de Janeiro: Campos, 1998.

16. MINTZBERG, H.; WATERS, J. A. Of strategies, deliberate and emergent. Strategic Management Journal, v. 6, p. 257-272, 1985.

17. OSTERWALDER, A; PIGNEUR, Y. Inovação em Modelos de Negócio: business Model Generation. 1. ed. Rio de Janeiro: Alta Books, 2011

18. OVIATT, B.M.; MCDOUGALL, P.P. Toward a theory of international new ventures. Journal of International Business Studies, 25/1, 45-64, 1994.

19. OVIATT, B.M.; MCDOUGALL, P.P. Global start-ups: entrepreneurs on a worldwide stage. Academy of Management Executive, 9/2, 30-43, 1995.

20. PENROSE, E. T. The theory of the growth of the firm. New York: John Wiley, 1959.

21. PORTER, M. E. Competitive advantage. New York: Free Press, 1985.

22. PORTER, M. E. Estratégia competitiva: técnicas para análise de indústrias e da concorrência. 7. ed. Rio de Janeiro: Campus, 1986. 
23. ROOT, F. R. Entry Strategies for the international Markets. New York: Lexington Books, 1994.

24. RIES, Eric. A Startup Enxuta: como os empreendedores atuais utilizam a inovação contínua para criar empresas extremamente bem-sucedidas. Tradução de Texto Editores. São Paulo: Lua de Papel, 2012

25. SCHUMPETER, Joseph. O Fenômeno Fundamental do Desenvolvimento Econômico. In $A$ Teoria do Desenvolvimento Econômico. Rio de Janeiro: Nova Cultural, 1985.

26. TURBAN, Efraim et al. Tecnologia da Informação para Gestão: Transformando os Negócios na Economia Digital 6ed. Bookman, 2004.

27. VERGARA, Sylvia Constant. Métodos de coleta de dados no campo. São Paulo: Editora Atlas S.A., 2009.

28. YIN, Robert K. Estudo de caso: planejamento e métodos. $2^{\mathrm{a}}$ ed. - Porto Alegre: Bookman, 2001.

29. WERNERFELT, B. A resource-based view of the firm. Strategic Management Journal, v. 5, n. 2, p. 171-180, 1984.

30. WOOLF. J. A.; PETT, T. L. Internationalization of small firms: an examination of export competitive patterns, firm size, and export performance. Journal of Small Business Management, v. 38, p. 34-47, 2000. 